\title{
Effect of pozzolans with different physical and chemical characteristics on concrete properties
}

\author{
H. Paiva ${ }^{\mathrm{a}} \bowtie$, A. Velosa ${ }^{\mathrm{b}}$, P. Cachim ${ }^{\mathrm{b}}$, V.M. Ferreira ${ }^{\mathrm{a}, \mathrm{b}}$ \\ a. Civil Engineering Dept./CICECO, University of Aveiro, (Aveiro, Portugal) \\ b. Civil Engineering Dept./RISCO, University of Aveiro, (Aveiro, Portugal) \\ \hpaiva@ua.pt
}

\author{
Received 24 February 2015 \\ Accepted 16 September 2015 \\ Available on line 12 April 2016
}

\begin{abstract}
The durability of concrete structures is an important issue nowadays. Specifically in the case of reinforced concrete bridges or other infrastructures one of the main form of environmental attack is the penetration of chloride ions, which leads to corrosion of concrete steel reinforcement.

This study aims to evaluate the effect of the introduction of metakaolin and diatomite, two chemically and physically different pozzolans, on the resistance of concrete to the penetration of chlorides but also the effect on other properties of concrete, namely, its compressive strength and its porosity distribution.

The results of this study show that the pozzolans physical and chemical characteristics have a strong influence on the pozzolans behavior and, consequently, on the concrete properties.
\end{abstract}

KEYWORDS: Concrete; Metakaolin; Pozzolans; Durability; Physical properties

Citation/Citar como: Pavía, H.; Velosa, A.; Cachim, P.; Ferreira, V.M. (2016) Effect of pozzolans with different physical and chemical characteristics on concrete properties. Mater. Construcc. 66 [322], e083. http://dx.doi.org/10.3989/ mc.2016.01815.

RESUMEN: Efecto de puzolanas con características físicas y químicas diferentes sobre las propiedades del hormigón. La durabilidad de las estructuras de hormigón es un tema importante hoy en día. En concreto, en el caso de los puentes de hormigón armado u otras infraestructuras, el principal factor de agresión medioambiental es la penetración de iones cloruro, lo que conduce a la corrosion del acero de refuerzo del hormigón. Este estudio tiene como objetivo evaluar el efecto de la introducción de metacaolín y diatomita, dos puzolanas química y físicamente diferentes, sobre la resistencia del hormigón a la penetración de cloruros, y también sobre otras de sus propiedades como la distribución de su porosidad o su resistencia a compresión.

Los resultados de este estudio muestran que las características fisicoquímicas de las puzolanas tienen una fuerte influencia en su comportamiento y en consecuencia, en las propiedades del hormigón.

PALABRAS CLAVE: Hormigón; Metacaolín; Puzolanas; Durabilidad; Propiedades físicas

Copyright: (C) 2016 CSIC. This is an open-access article distributed under the terms of the Creative Commons Attribution-Non Commercial (by-nc) Spain 3.0 License.

\section{INTRODUCTION}

The concrete structures are often exposed to harsh environments and, for instance, in the case of reinforced concrete bridges, the main form of environmental attack is the penetration of chloride ions, which leads to corrosion of the concrete steel reinforcement and reduction in strength and weak aesthetics, which usually results in early repairs or premature structure replacement. This creates a problem in the construction materials sector. Generally, it is expected that these structures may 
last, with little or no maintenance, for long periods of time. Production of highly resistant concrete structures is required nowadays, which is patent by the increase of studies concerning concrete durability. One way to prevent this deterioration is to avoid the penetration of chlorides in the concrete by making the structure more impermeable. Currently, the use of pozzolanic materials in partial replacement of Portland cement in concrete production is widely accepted. In addition to the environmental benefit related to the decrease of $\mathrm{CO}_{2}$ emissions, the use of pozzolans have technical advantages, particularly in terms of increasing the durability of concrete regarding corrosion, carbonation and attack by sulphates, among other factors that may shorten the service life of structures based on the use of Portland cement (1).

Metakaolin is one of the pozzolanic materials that have been widely studied recently. The inclusion of metakaolin improves the mechanical properties and durability of concrete due to its high pozzolanic activity (2). Metakaolin shows in its constitution amorphous silica but also amorphous alumina that, in presence of water, quickly reacts with calcium hydroxide mainly producing calcium aluminate hydrates and aluminiumsilicate hydrates. Siddique et al. (3) in a study about the influence of metakaolin on mortar and concrete properties shows several advantages, specifically, an increase of mechanical strength and durability, but also a decrease of shrinkage due to the increase of material density and a better particle packing.

Park et al. (4) have evaluated the crack effect on chloride diffusion, using accelerated migration test in non-stationary condition on concrete specimens with various crack widths. These authors concluded that chloride diffusion coefficient in cracked concrete increases rapidly with crack width and a relationship was obtained. Yang et al. (5) have shown in their work that the external flexural loading accelerate the concrete deterioration and that concrete subjected to both sulfate and chloride attack suffers less damage than that which is prone to sulfate attack alone. Chloride ions in concrete can reduce and/or delay the deterioration of concrete attacked by sulfate ions.

Khatib and Clay (6) have studied the effect of replacing cement by metakaolin in contents from 0 to $20 \%$, keeping constant the water amount, finding that the presence of metakaolin reduces water penetration by capillary action. Metakaolin is obtained by the calcination of kaolinitic clays at temperatures from 650 to $800^{\circ} \mathrm{C}$. Metakaolin (MK) presents a high reactivity with calcium hydroxide, $\mathrm{Ca}(\mathrm{OH})_{2}$, and an ability to accelerate cement hydration due to its high concentration of silica and alumina. The calcium to silicon $(\mathrm{C} / \mathrm{S})$ ratio of the produced calcium silica hydrates $(\mathrm{C}-\mathrm{S}-\mathrm{H}$ gel) is very high, leading to a considerably improved concrete microstructure and better overall performance of concrete, in terms of strength, porosity, permeability, chloride ion diffusivity and freeze-thaw resistance (7-9).

In concrete, chloride ions may be free in the solution within the pores or may be physically bound with the cement hydration products. The ability of cementitious products to connect with the chloride ions reduces the rate of transport of chloride ions into the concrete. The rate of reduction of chloride ions depends on their ability to link chemically with the hydration products. The partial replacement of pozzolan in cement, either using flyash or metakaolin, specifically involves the additional formation of hydrated products, thus increasing the binding ability, in comparison with a concrete using cement as the sole binder. Thus, the total chloride concentration (free or bound) in the outer layers of a concrete with pozzolans may be equal to or greater than the concentration in a concrete only with cement $(10,11)$. Simultaneously, due to the products formed by the pozzolanic reaction inside the capillary pores, in addition to increasing the binding capacity of the cementitious matrix, the pore system also becomes thinner and more segmented, hindering the diffusion of chlorides $(10,11)$.

Many others authors tried to study and understand the action of chloride ions in concrete. Linnhua Jiang et al. (12) studied the influence of chloride salt type on the level of reinforced concrete corrosion and concluded that the chloride salts with the same valence cation as $\mathrm{NaCl}$ and $\mathrm{KCl}$ have an identical behavior. However, chloride salts with different valence cations, as $\mathrm{MgCl}_{2}$ and $\mathrm{CaCl}_{2}$ have a higher threshold level for the corrosion than $\mathrm{NaCl}$ and $\mathrm{KCl}$, when added to the cement.

Zhiguang et al. (13) studied the combined effect of metakaolin and seawater on the properties and microstructures of concrete. The compressive strength, pore structure, hydration products and microstructure of concrete were affected by the addition of MK and mixing with seawater. The highest compressive strength was obtained by addition of $5 \mathrm{wt} \%$ of metakaolin and mixing with seawater, which increased the compressive strength by $52 \%$ at 28 days. They also observed that concrete chloride resistance increased with the amount of metakaolin. Mixing with seawater was able to improve the chloride resistance.

Diatomite (DT) is a natural material from a sedimentary rock, formed mainly by the deposition of microscopic organisms with a crystalline and amorphous silica shell (14). Diatomite can be used as a pozzolan, directly after milling or after a heat treatment at about $1000{ }^{\circ} \mathrm{C}$ followed by grinding. Subjecting this material to thermal treatment shows an increase in the content of amorphous silica and grinding reduces its particle size. The hydraulic and pozzolanic activity of silica mineral additions depends on its crystalline or amorphous state as well 
as on its size and particle shape (15). Some authors have shown that the use of diatomite in the production of mortar and concrete does not improve its mechanical properties $(14,16)$.

A disadvantage of the use of diatomite in the production of mortar and concrete is the need of a high amount water, due to diatomite high porosity, which promotes a reduction in the mechanical strength $(17,18)$.

Several authors agree that the use of metakaolin also promotes a decrease in workability. This effect requires an increase in the amount of mixing water or the use of high range water reducing admixture (HRWRA) to increase the workability. The water reducing agents allow reducing the mixing water keeping the same workability or, increase the system fluidity without increasing the water content (19-21). The increase in the system fluidity due to the addition of a high range water reducing admixture (HRWRA) is a consequence of its adsorption on the particle surface, which deflocculates, releasing water to lubricate the system and facilitate the air expulsion retained inside the particles agglomerates (19-21).

This study evaluates the effect of the introduction of metakaolin and diatomite on basic properties but also on the resistance of concrete to the penetration of chlorides, using two distinct evaluation methods (quantitative and qualitative) to determine the chloride content in the concrete by means of samples immersed in an artificial saline solution.

\section{MATERIAL AND METHODS}

\subsection{Materials}

In this study the formulation for the reference concrete mixture was determined using the Faury method. The concrete was produced with $350 \mathrm{~kg}$ of cement per $\mathrm{m}^{3}$ of concrete and having a water/ cement ratio of 0.6 . The standard concrete (B_0.6W) constitution involves Portland cement (CEM type I 42.5R) (Cimpor) as a binder, a siliceous natural sand (S) (A. Santos) and two types of crushed limestone (B1and B2) (A. Santos and Parapedra) as aggregate, the particle size distributions of which are presented in Table 1.

The fundamental formula for this concrete can be written as:

$[350 \mathrm{~kg}$ cement $+423.2 \mathrm{~kg} \mathrm{~S}+892.7 \mathrm{~kg} \mathrm{~B} 1+406.1 \mathrm{~kg}$ $\mathrm{B} 2+210 \mathrm{~kg}$ water $=1 \mathrm{~m}^{3}$ concrete]

The concrete was produced in a special laboratory mixer $(35 \mathrm{Kg})$. The standard concrete presents workability inside a range of 8 to $10 \mathrm{~cm}$ (slump).

Metakaolin (MK) (Argical) was used as a partial cement substitute in contents of 10, 20 and $30 \mathrm{wt} \%$. This material is a dehydroxylated aluminium silicate with a general formula of $\mathrm{Al}_{2} \mathrm{O}_{3} \cdot 2 \mathrm{SiO}_{2}$. It is an amorphous non-crystallized material constituted of lamellar particles. This MK presents a pozzolanic index (measured by the Chapelle test) of $1100 \mathrm{mg}$ $\mathrm{Ca}(\mathrm{OH})_{2}$ per gram of metakaolin and a specific surface area (BET) of $17 \mathrm{~m}^{2} / \mathrm{g}$.

Diatomite (Minerals I Derivats) was calcined and ground and presents a specific surface area (BET) of $8 \mathrm{~m}^{2} / \mathrm{g}$. The Chapelle test was not conducted in diatomite because the method residence time of contact with the calcium hydroxide $\left(\mathrm{Ca}(\mathrm{OH})_{2}\right.$ is not enough to obtain reliable results. Because of that, a comparative study, adapted to evaluate pozzolanic reactivity, was performed for both pozzolanic materials. This test compares the compressive strength of mortars with metakaolin or with diatomite based on the pozzolan reaction with hydrated lime (Lusical). The choice of lime as a binder was due to the fact that calcium hydroxide reacts with pozzolans. This method consists in the production of a reference lime mortar with a composition of $80 \%$ of sand and $20 \%$ hydrated lime (purity $90 \% \mathrm{Ca}(\mathrm{OH})_{2}$ ). In these mortars $50 \%$ of lime was replaced by diatomite or metakaolin.

Table 2 presents the metakaolin and diatomite chemical analysis. The metakaolin presents as major

TABle 1. Aggregate particle size distribution

\begin{tabular}{lccc}
\hline Sieve size (mm) & $\begin{array}{c}\text { Natural siliceous sand } \\
\text { (Cumulative \% passing) }\end{array}$ & $\begin{array}{c}\text { Crushed aggregate I } \\
\text { (Cumulative \% passing) }\end{array}$ & $\begin{array}{c}\text { Crushed aggregate II } \\
\text { (Cumulative \% passing) }\end{array}$ \\
\hline 31.5 & 100.0 & 100.0 & 100.0 \\
16 & 100.0 & 100.0 & 100.0 \\
8 & 100.0 & 100.0 & 24.5 \\
4 & 100.0 & 59.9 & 0.6 \\
2 & 99.8 & 12.2 & 0.5 \\
1 & 98.8 & 4.9 & 0.5 \\
0.500 & 82.9 & 3.8 & 0.5 \\
0.250 & 19.4 & 3.3 & 0.5 \\
0.125 & 1.3 & 0.9 & 0.4 \\
0.063 & 0.5 & 0.3 & 0.4 \\
\hline
\end{tabular}


TABLE 2. Cement (C), metakaolin (MK) and diatomite (D) chemical analysis

\begin{tabular}{lccccccccccc}
\hline & $\mathrm{SiO}_{\mathbf{2}}(\%)$ & $\mathrm{Al}_{2} \mathbf{O}_{\mathbf{3}}(\%)$ & $\mathrm{Fe}_{2} \mathbf{O}_{\mathbf{3}}(\%)$ & $\mathbf{M n O}(\%)$ & $\mathbf{M g O}(\%)$ & $\mathbf{C a O}(\%)$ & $\mathrm{Na}_{\mathbf{2}} \mathbf{O}(\%)$ & $\mathbf{K}_{\mathbf{2}} \mathbf{O}(\%)$ & $\mathrm{TiO}_{2}(\%)$ & $\mathbf{P}_{2} \mathbf{O}_{\mathbf{5}}(\%)$ & $\mathbf{P . R} .(\%)$ \\
\hline $\mathrm{C}$ & 22.23 & 5.70 & 3.50 & 0.09 & 1.13 & 63.30 & nd & 0.86 & 0.28 & 0.10 & 3.13 \\
$\mathrm{MK}$ & 52.17 & 44.50 & 0.45 & nd & nd & 0.01 & nd & 0.15 & 1.42 & 0.12 & 1.42 \\
$\mathrm{D}$ & 81.71 & 0.56 & 0.31 & 0.01 & 0.14 & 7.29 & nd & 0.08 & 0.05 & 0.06 & 10.16 \\
\hline
\end{tabular}

nd: not determinated

components $\mathrm{SiO}_{2}$ and $\mathrm{Al}_{2} \mathrm{O}_{3}$, while the diatomite presents mainly $\mathrm{SiO}_{2}$. This chemical difference is one of the reasons why the metakaolin displays higher pozzolanic reactivity at an initial stage, since the formed aluminates react faster than silicates.

The X-ray diffraction (XRD) was also performed and the cement (Figure 1) presents as minor elements tricalcium aluminate $(\mathrm{C} 3 \mathrm{~A})$ and tetracalcium aluminoferrate $\left(\mathrm{C}_{4} \mathrm{AF}\right)$. The other XRD peaks are related to anhydrous compounds and gypsum present in the composition of the Portland cement used (type I). The diffraction pattern of metakaolin is shown in Figure 2 and the diatomite one is in Figure 3.

Analyzing the results of the chemical tests, it is apparent that the metakaolin has alumina and silica. The diatomite has only silica as major element in its constitution. The two pozzolans are chemically different. The two pozzolans are also physically different being the diatomite a very high porosity material.

The water reducing admixture (BASF) is based in polycarboxylic acid with a density between 0.7 and 1.1 and solid content between 28.5 and $31.5 \%$.

Table 3 shows the studied concrete compositions. The water/binder ratio was kept constant at 0.6, considering as binder the cement and the pozzolan together. The workability of all formulations was also kept inside the range presented by the standard concrete (slump between 8 and $10 \mathrm{~cm}$ ). For that propose a water reducing agent (WR) was used.

\subsection{Methods}

\subsubsection{Chlorides ions penetration}

The durability of concrete was evaluated in some compositions through its resistance to chloride ions penetration using two different methods, a quantitative and a qualitative one. In both methods samples after demolding are cured in conditioned environment chamber $\left(20 \pm 5^{\circ} \mathrm{C}\right.$ and $\left.95 \pm 5 \% \mathrm{RH}\right)$ for 28 days and then immersed in a saline solution (composition in Table 4) for six months. The intention of using this saline solution was to simulate the composition of sea water, with sodium chloride as predominant element (22). After this time, samples were tested, in terms of the level of penetration of chlorides with two different types of test methods.

In the quantitative method, $100 \times 100 \times 100 \mathrm{~mm}^{3}$ cubic samples were used and, prior to immersion, they were sealed with a resin on four of its sides, allowing two opposing sides to be exposed to the saline solution (10). After six months of immersion, the samples, after drying were cut into two equal

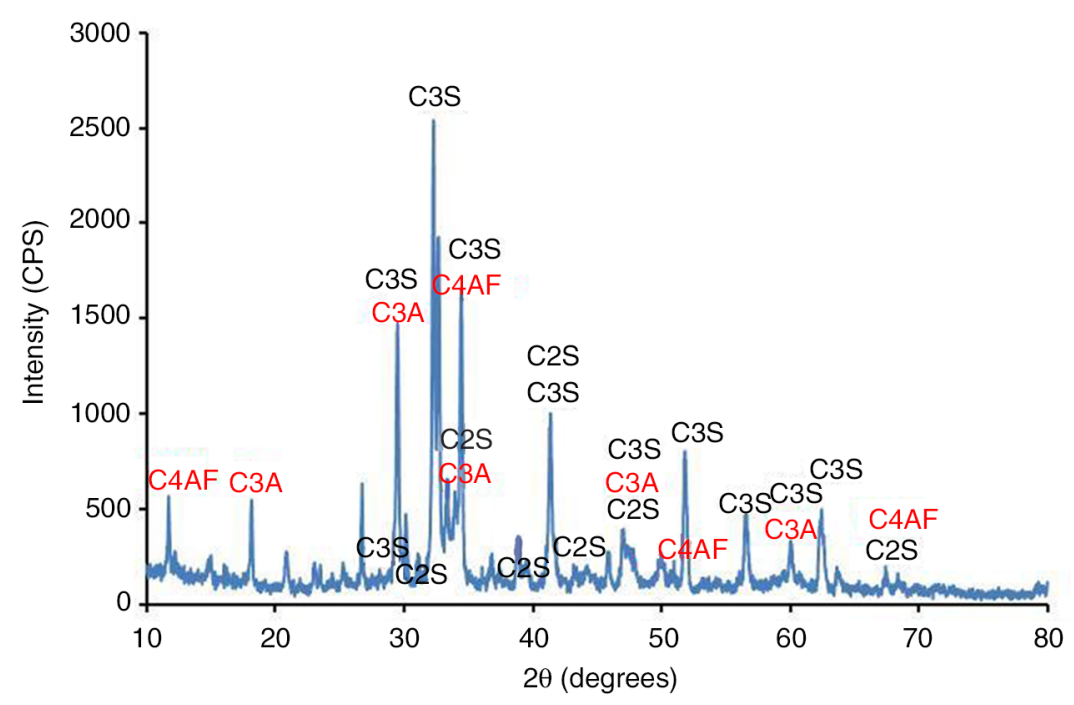

Figure 1. Cement X-ray diffraction. 


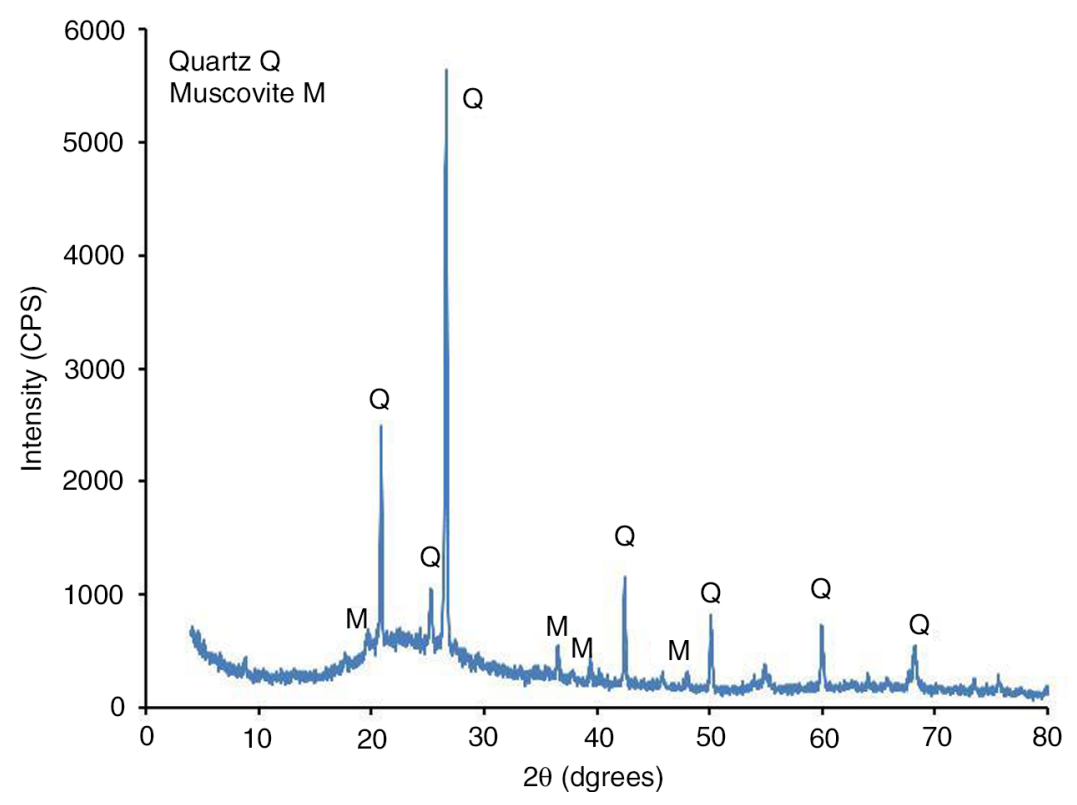

Figure 2. Metakaolin X-ray diffraction.

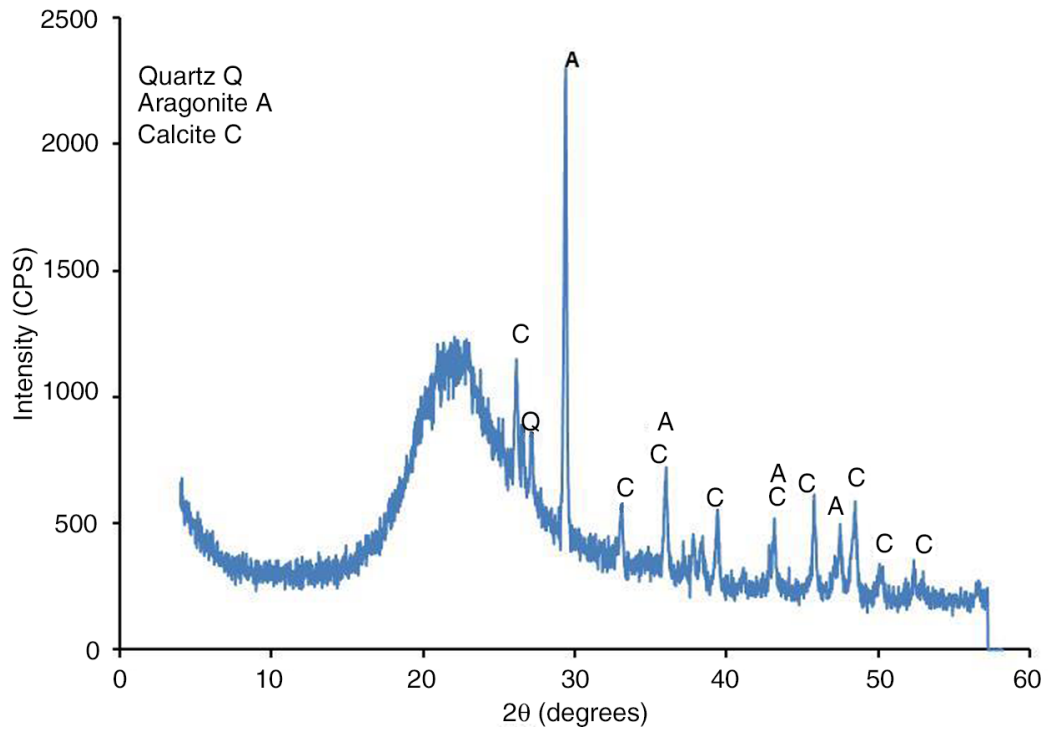

FIGURE 3. Diatomite X-ray diffraction.

parts. One of the halves was cut into three slices of about $15.6 \mathrm{~mm}$ each (Figure 4). Thus a portion of the exterior of the test piece, which was immediately in contact with water, is obtained, but also a second slice of the intermediate region and a third slice from the center of the specimen were also analysed. Each slice is subjected to grinding to obtain a powder with a particle size below $150 \mu \mathrm{m}$, followed by a process in which $5 \mathrm{~g}$ of each sample is dissolved in $100 \mathrm{ml}$ of $\mathrm{HNO}_{3}$ at $10 \%$ (weight/weight) and boiled for 25 minutes. The sample is then filtered with the aid of distilled water to a volume of $500 \mathrm{ml}$. The determination of chloride content is performed by potentiometry using a selective ion electrode (Consort, model C860), according to EN 1015-17:2000 (Determination of water-soluble chloride content of fresh mortars). With this procedure, a profile of penetration of chlorides $(\mathrm{mg} / \mathrm{kg}$ of concrete) from the outside to the center of the sample was obtained. 
TABLE 3. Studied concrete formulations

\begin{tabular}{|c|c|c|c|}
\hline Composition & $\begin{array}{c}\text { Pozzolan } \\
(\%)\end{array}$ & $\begin{array}{l}\text { Water I } \\
\text { binder }\end{array}$ & $\begin{array}{l}\text { WR content (wt } \% \\
\text { of total solids) }(\%)\end{array}$ \\
\hline $\begin{array}{l}\text { Standart concrete } \\
\text { B_0.6W }\end{array}$ & 0 & 0.60 & 0 \\
\hline B_xMK_yW_zWR & $\begin{array}{l}5,10,15,20 \\
25 \text { and } 30\end{array}$ & 0.60 & 0 to 0.25 \\
\hline B_xD_yW_zWR & $3 ; 5 ; 8 ; 10$ & 0.60 & 0 to 0.12 \\
\hline
\end{tabular}

TABLE 4. Saline solution composition

\begin{tabular}{lc}
\hline Component & Concentration (g/l) \\
\hline $\mathrm{NaCl}$ & 30.0 \\
$\mathrm{MgCl}_{2}$ & 6.0 \\
$\mathrm{MgSO}_{4}$ & 5.0 \\
$\mathrm{CaSO}_{4} \cdot 2 \mathrm{H}_{2} \mathrm{O}$ & 1.5 \\
$\mathrm{KHCO}_{3}$ & 0.2 \\
\hline
\end{tabular}

For the qualitative test (23), cylindrical samples with dimensions of $300 \mathrm{~mm}$ (height) and $150 \mathrm{~mm}$ (diameter) were used, which after curing and after remaining in the above-mentioned saline environment for 6 months, are splited longitudinally for observation and tests. The cylinder is opened in two parts and is then sprayed with silver nitrate, that reacting with chlorides, gives rise to a silver gray color. The intensity of the color provides an indication of penetration depth, from the exterior to the interior of the sample, enabling the comparison of salt penetration in the various compositions.

\subsection{Other characterization tests}

Thermal analysis (differential and thermogravimetric analysis) was also used to calculate the consumption ratio of $\mathrm{Ca}(\mathrm{OH})_{2}$ in the cementitious matrix due to the pozzolans introduction. Also the compressive strength test according to NP EN 206-1, using a testing machine (FORM+TEST type Beta 2 3000D) and sample tests with dimension of $100 \times 100 \times 100 \mathrm{~mm}^{3}$ were performed. Before testing the samples were cured in a chamber at $20^{\circ} \pm 5^{\circ} \mathrm{C}$ and $95 \pm 5 \% \mathrm{RH}$ during 28 days.

Porosity measurements were also carried out on hardened samples by mercury intrusion porosimetry (MIP), which allows assessing not only the total porosity but also the pore size distribution. The samples preparation involved the separation of the mortar part from the coarse aggregate. Only the mortar part was analyzed.

\section{RESULTS AND DISCUSSION}

\subsection{Metakaolin and diatomite pozzolanic reactivity}

Table 5 presents the results for the compressive strength (Rc) showed by the reference or base mortar and the mortars with metakaolin or diatomite at different cure times.

The results show that the reaction of the metakaolin with calcium hydroxide is more rapid and extensive. It can be concluded that metakaolin have higher pozzolanic reactivity than the diatomite.

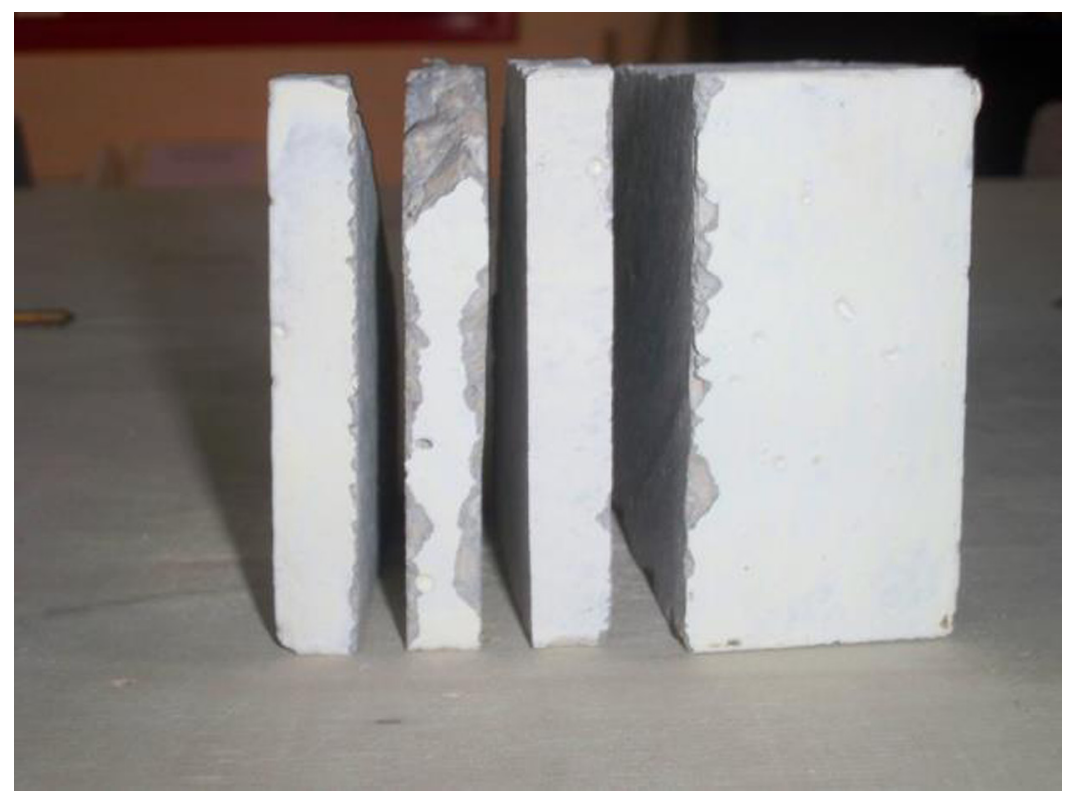

Figure 4. Concrete sample with 28 days of curing in a controlled environment and 6 months in a saline solution, cut into three slices from the outside to the inside of the sample. 


\subsection{Effect of metakaolin and diatomite on concrete properties}

Tables 6 and 7 shows the results of the chloride concentration measured by the quantitative and qualitative methods, respectively, for some concrete compositions with metakaolin and diatomite, with

TABLE 5. Values of compressive strength for the different lime mortar compositions at several curing times

\begin{tabular}{lcccc}
\hline Composition & $\begin{array}{c}\text { Rc (MPa) } \\
\text { 24 hours }\end{array}$ & $\begin{array}{c}\text { Rc (MPa) } \\
\text { 3 days }\end{array}$ & $\begin{array}{c}\text { Rc (MPa) } \\
\text { 7 days }\end{array}$ & $\begin{array}{c}\text { Rc (MPa) } \\
\text { 28 days }\end{array}$ \\
\hline Base mortar & - & 0.29 & 0.29 & 0.47 \\
Mortar with & 0.29 & 1.01 & 2.99 & 3.73 \\
MK & & & & \\
Mortar with D & - & 0.41 & 0.62 & 1.08 \\
\hline
\end{tabular}

TABLE 6. Values of $\mathrm{Cl}^{-}$content in the different studied compositions

\begin{tabular}{llc}
\hline Concrete composition & Sample zone & Cl $^{-}$(mg/kg) \\
\hline Standart concrete B_0.6W & Exterior & $2452 \pm 123$ \\
& Middle & $1197 \pm 60$ \\
& Center & $673 \pm 27$ \\
B_10MK_0.6W_0.10WR & Exterior & $3020 \pm 85$ \\
& Middle & $543 \pm 25$ \\
& Center & $187 \pm 27$ \\
B_20MK_0.6W_0.15WR & Exterior & $3020 \pm 85$ \\
& Middle & $290 \pm 12$ \\
& Center & $101 \pm 12$ \\
B_5D_0.6W_0.08WR & Exterior & $2469 \pm 99$ \\
& Middle & $379 \pm 14$ \\
& Center & $193 \pm 6$ \\
B_8D_0.6W_0.10WR & Exterior & $2544 \pm 94$ \\
& Middle & $478 \pm 15$ \\
& Center & $195 \pm 10$ \\
& Middle & $246 \pm 10$ \\
& Center & $178 \pm 9$ \\
\hline
\end{tabular}

TABle 7. Depth of $\mathrm{Cl}^{-}$penetration in the different studied compositions

\begin{tabular}{lcc}
\hline Compositions & $\begin{array}{c}\text { Depth of } \\
\text { penetration (mm) }\end{array}$ & $\begin{array}{c}\text { Depth of } \\
\text { penetration } \\
\text { average (mm) }\end{array}$ \\
\hline B_0.60W & 30 to 40 & $35 \pm 5$ \\
B_20MK_0.60W_0.15WR & 7 to 9 & $8 \pm 1$ \\
B_3D_0.60W_0.05WR & 28 to 35 & $31.5 \pm 3.5$ \\
B_5D_0.60W_0.08WR & 18 to 21 & $19.5 \pm 1.5$ \\
B_8D_0.60W_0.10WR & 15 to 18 & $16.5 \pm 1.5$ \\
B_10D_0.60W_0.12WR & 13 to 15 & $14 \pm 1$ \\
\hline
\end{tabular}

workability adjustment performed through the use of a water reducing agent (WR). Metakaolin particles are very small and have a great tendency to form agglomerates, creating "large particles", which decrease metakaolin reactivity.

The separation of fine particles promoted by the presence of the water reducing agent increases the system reactivity, accelerating the hydration and pozzolanic reactions providing high amounts of the reaction products with the ability to bind the chloride ions. This decrease is higher in compositions with metakaolin confirming its higher pozzolanic reactivity. Of course, metakaolin and diatomite also have the ability to react with other salts besides the chlorides present in the seawater-type saline solution. Nevertheless, the tests used here measure the reaction with chlorides, the salt present with highest concentration, and that is what is reported here.

Figure 5 clearly shows the behaviour of the chloride ions penetration into the concrete with different pozzolans. The concrete workability was adjusted using a water reducing agent and keeping fixed the water amount.

Compositions with 10 and 20\% metakaolin present, in the external zone, higher concentrations of the chlorides ions when compared to the base concrete. The metakaolin high pozzolanic reactivity promotes an increase in the quantity of reaction products with the ability to chemically link the chloride ions. At same time, as the reaction produts were formed inside the capillary pores, the pore system becames thinner and segments, hindering the diffusion of chloride ions into samples center. In Figure 5 it is possible observed that the compositions with metakaolin presents a very lower concentration of chloride ions than the standard composition.

Concrete with diatomite show a chloride ion concentration similar to that shown by the base concrete in the sample surface but quickly there is a decrease in chloride concentration towards the center of the samples. Apparently, although the diatomite has a lower pozzolanic reactivity than metakaolin, its reaction with sodium hydroxide and consequent system densification is sufficient to decrease the diffusion of chloride ions into the center of the sample.

Figure 6 present the pore size distribution in standard concrete mortar and mortars with $20 \%$ MK, $5 \% \mathrm{D}$ and $10 \% \mathrm{D}$. As expected, the metakaolin compositions have the smallest amount of capillary pores although they show a high number of small pores. The formulation with $5 \%$ of diatomite presents a high level of porosity but with the increase of diatomite amount $(10 \%)$ the porosity decreases until the level of the concrete base mortar.

The diatomite is physically and chemically different from metakaolin. The diatomite has an intrinsic high porosity but its surface area is lower than that presented by metakaolin. Chemically, diatomite has not in its constitution amorphous alumina, which is 
(a)
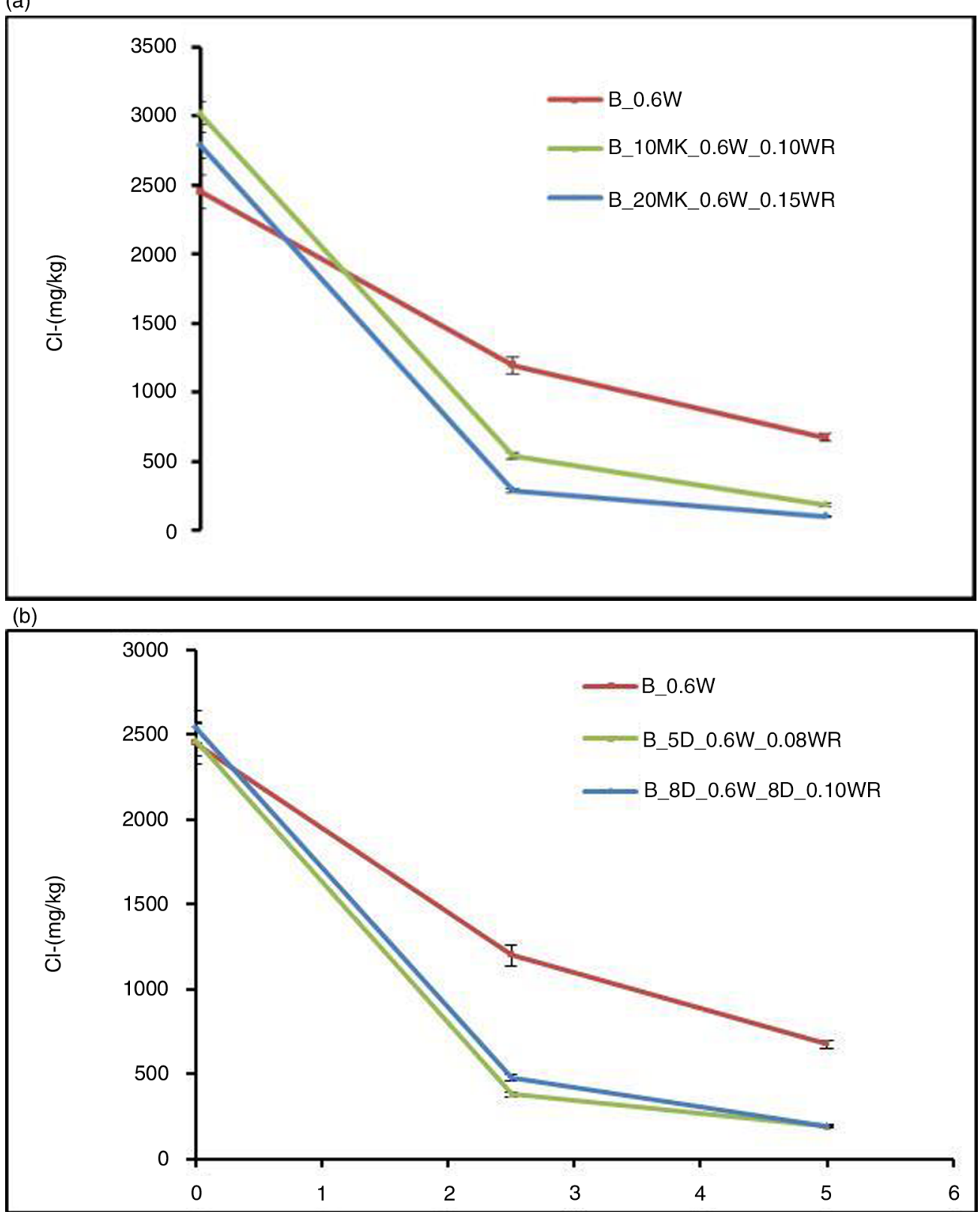

FIGURE 5. Chlorides penetration values in concrete samples with metakaolin and diatomite from the exterior to the center of the samples.

a component that reacts very quickly with calcium hydroxide. These factors justify its lower reaction rate with calcium hydroxide. However, the increase in the diatomite content accelerates the pozzolanic reaction and improves its performance.

The use of pozzolans is beneficial for the durability of concrete; however, the physical and chemical characteristics of each used pozzolan influence the microstructure of concrete and properties of concrete. Table 8 shows the consumption of calcium hydroxide by the different compositions, with different curing times, compared with the base concrete composition. It is possible to observe in base concrete an increase in the calcium hydroxide amount due to the evolution of cement hydration. The compositions with pozzolan present a decrease in the calcium hydroxide content due to the pozzolanic reactions. It is also clear that metakaolin reacts more, since the consumption of calcium hydroxide was higher. As the cement hydration reactions and the pozzolans reactions occurr within the capillary pores, they also promote a system densification. A higher pozzolanic reaction promotes a high amount of reaction products, capable of binding 


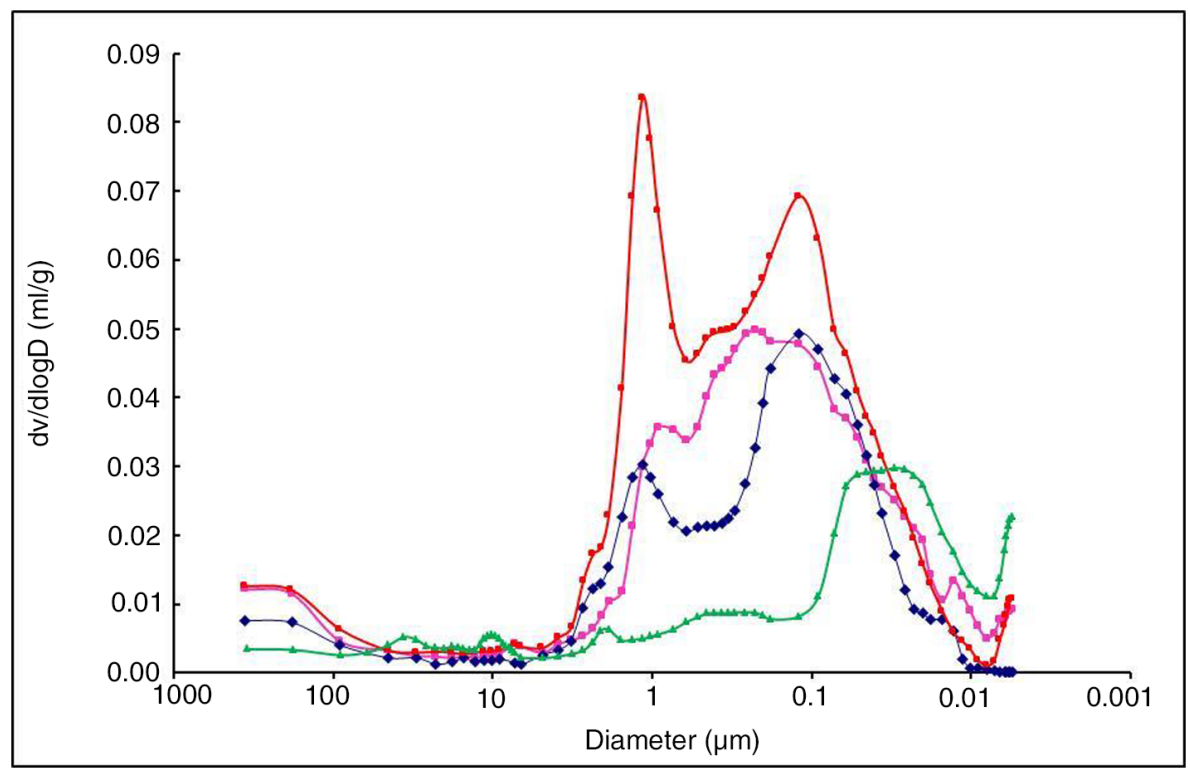

FIGURE 6. Pore size distribution in standard concrete mortar and mortars with $20 \% \mathrm{MK}, 5 \% \mathrm{D}$ and $10 \%$ D, after 28 days of curing (Blue: Standard; Red: $5 \%$ of D; Rose: $10 \% \mathrm{D}$; Green: $20 \% \mathrm{MK}$ ).

chloride ions and preventing them to disseminate into the concrete. Moreover, the densification of the system also makes the chloride ions diffusion more difficult. This effect was observed in the chlorides penetration tests, where metakaolin compositions were very effective in increasing the resistance to penetration of chlorides (Figure 5).

The effect of density increase in concrete formulations with metakaolin can also be seen in Figure 7. Figure 7 shows the compressive strength values for the different studied concrete mixtures. It is possible to observe that the compressive strenght values increase with the increase of metakaolin content.

The system densification promoted by the compositions with diatomite is not higher than the metakaolin ones, due to a lower consumption of calcium hydroxide (Table 8) and due to the diatomite high porosity that produces a more porous

TABLE 8. Amount of $\mathrm{Ca}(\mathrm{OH})_{2}$, calculated from thermal analysis

\begin{tabular}{lcc}
\hline Formulation & $\begin{array}{c}\text { Curing time } \\
\text { (days) }\end{array}$ & $\begin{array}{c}\mathrm{Ca}(\mathrm{OH})_{2} \text { (\% weight } \\
\text { of cement) }\end{array}$ \\
\hline B_0.6W & 7 & 11.9 \\
B_0.6W & 28 & 15.1 \\
B_20MK_0.6W_0.15SP & 28 & 2.9 \\
B_30MK_0.6W_0.20SP & 7 & 5.5 \\
B_30MK_0.6W_0.20SP & 28 & 1.6 \\
B_5D_0.6W_0.08SP & 28 & 12.4 \\
B_8D_0.6W_0.10SP & 28 & 7.4 \\
B_10D_0.6W_0.12SP & 28 & 5.4 \\
\hline
\end{tabular}

microstructure. These factors imply lower pozzolanic reaction products to bind to chloride ions and also an easier diffusion of chloride ions, due to the higher porosity of these concretes. However, there is an increased consumption of calcium hydroxide with the increase of diatomite content.

Regarding the results of the compressive strength provided by concrete with diatomite (Figure 7), it is found that concrete with $5 \%$ diatomite presents less strength than the base concrete and the concrete with 8 and $10 \%$ of diatomite show an increase in the compressive strength, in agreement with the observed porosimetry tests.

Figures 8 and 9 present the depth of penetration of chlorides measured by the qualitative method in some compositions with metakaolin and diatomite. Also in this method, it is possible to observe that the action of metakaolin is very effective in reducing the depth of penetration of chloride ions when compared with the base concrete. It is evident that the decrease in penetration depth is remarkable and the sample center shows no presence of chloride when metakaolin is added. A study of Wild et al. (22) found that metakaolin has a high pozzolanic reactivity but also the ability to accelerate the cement hydration producing a greater amount of portlandite to react with the metakaolin.

Regarding compositions with diatomite, there is also a tendency for a decrease in depth of chloride ions penetration by increasing the amount of diatomite introduced into the formulation. Figure 9 shows this effect but chlorides inside the sample with $5 \%$ diatomite can still be detected. Concrete with $10 \%$ diatomite shows a reduction of the diffusion of 


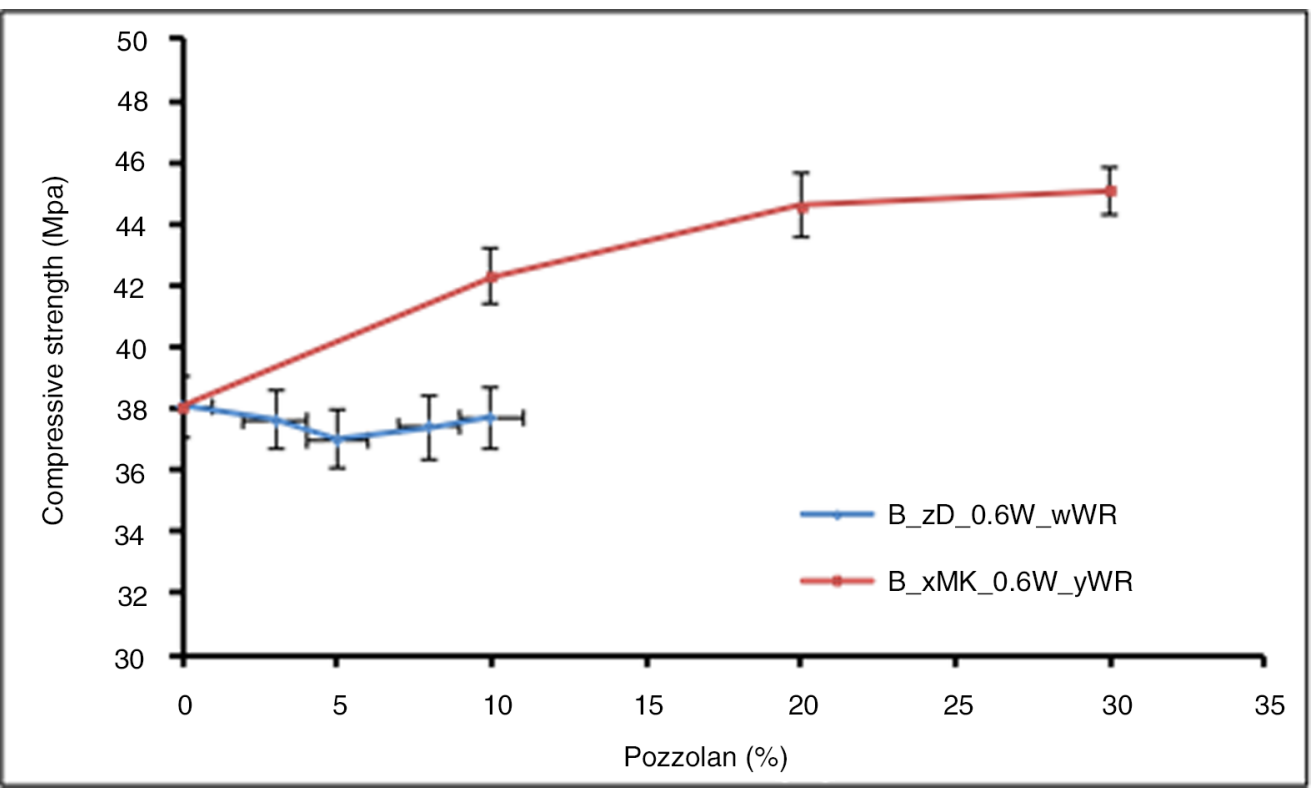

Figure 7. Compressive strength values of concretes with different pozzolan content.

(a)

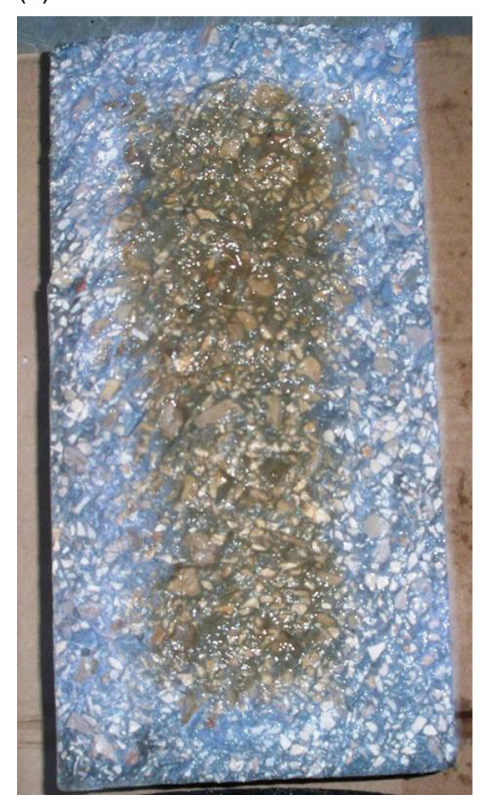

(b)

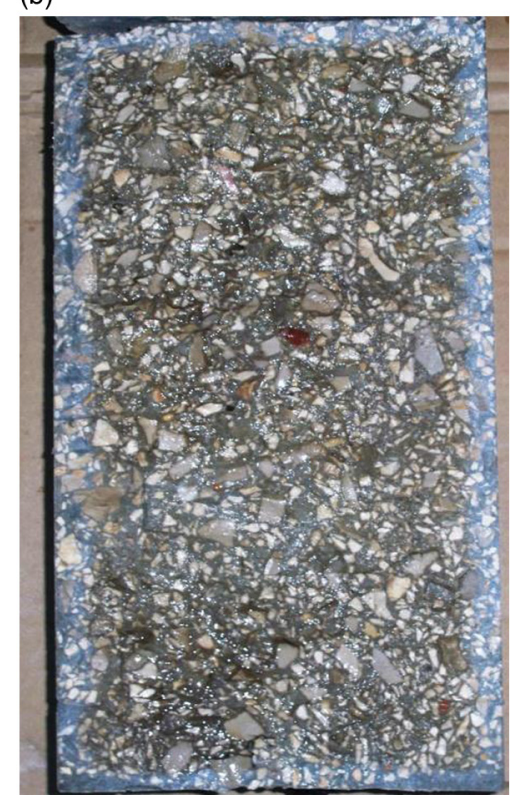

FIGURE 8. Base concrete and concrete with metakaolin sprayed with silver nitrate. It is possible to observe the extent of chloride ion penetration.

chlorides to the center. Diatomite addition is not as effective as the metakaolin.

\section{CONCLUSIONS}

The role of pozzolans in concrete was studied regarding its effects on the durability through the chloride penetrations tests and, at the same time, the consequences in the microstructure and mechanical properties were analysed.

Pozzolans used in concrete formulation were a metakaolin and a diatomite, different in composition, particle surface area and reactivity. Metakaolin's high pozzolanic reactivity ensures a high amount of pozzolanic reaction products, which enhance the ability to bind chloride ions and also densify the 
(a)

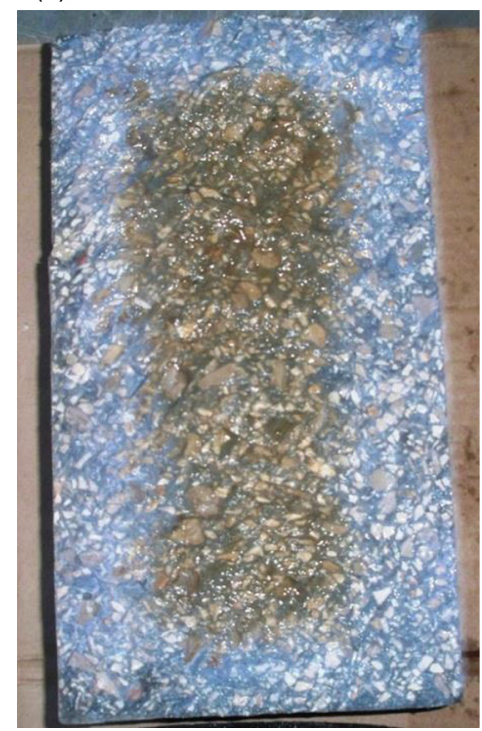

(b)

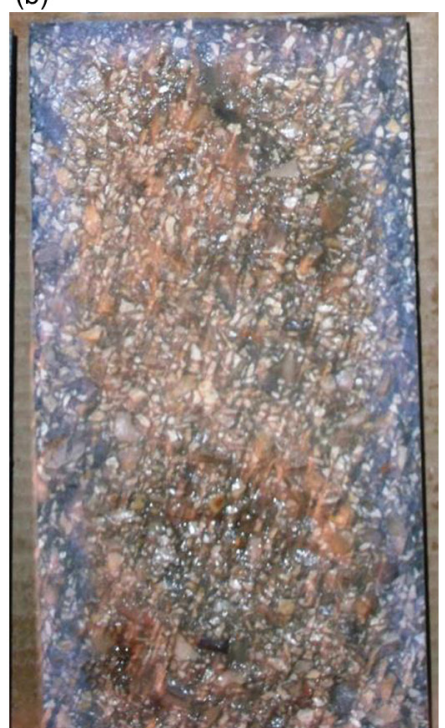

(c)

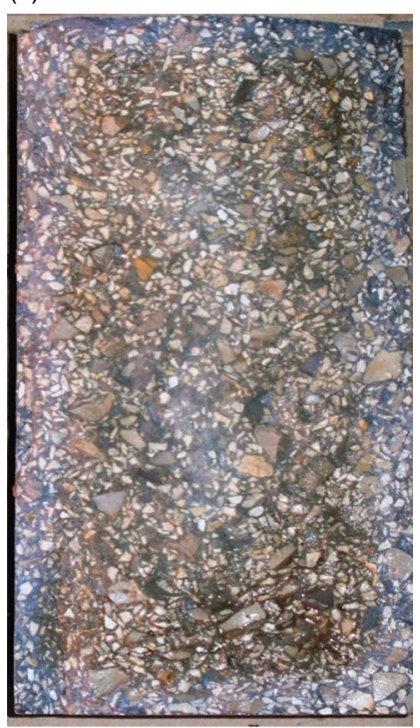

FIGURE 9. Base concrete and concrete with diatomite sprayed with silver nitrate. It is possible to observe the extent of chloride ion penetration.

cementitious matrix diffusion, leading to a higher durability. The diatomite, although with lower pozzolanic reactivity, can also decrease the penetration of chloride ions.

The use of pozzolans improves the resistance to chlorides penetration promoting a concrete with greater durability and this also reflects the changes in microstructure and measured mechanical properties.

\section{REFERENCES}

1. Glasser, F.P.; Marchand, J.; Samson, E. (2008) Durability of concrete - Degradation phenomena involving detrimental chemical reactions. Cem. Con. Res., 38, 226-246. http:// dx.doi.org/10.1016/j.cemconres.2007.09.015.

2. Hong-Sam, Kim; Sang-Ho; Han-Young Moon. (2007) Strenght properties and durability aspects of high strength concrete using Corean metakaolin. Cons. Build. Mat., 21, 1229-1237. http://dx.doi.org/10.1016/j.conbuildmat.2006. 05.007 .

3. Siddique, R.; Klaus, J. (2009) Influence of metakaolin on the properties of mortar and concrete a review. Appl. Clay. Sci., 43, 392-400. http://dx.doi.org/10.1016/j.clay.2008. 11.007 .

4. Sang-Soon Park; Seung-Jun Kwon; Sang Hwa Jung. (2012) Analysis technique for chloride penetration in cracked concrete using equivalent diffusion and permeation. Con. Build. Mat., 29, 183-192. http://dx.doi.org/10.1016/j.conbuildmat. 2011.09.019

5. Ding-yi Yang; Jing-jing Luo. (2012) The damage of concrete under flexural loading and saline solution. Con. Build. Mat., 36, 129-134. http://dx.doi.org/10.1016/j.conbuildmat. 2012.05.019.

6. Khatib, J.M.; Clay, R.M. (2004) Absorption characteristics of metakaolin concrete. Cem. Con. Res., 34, 19-29. http:// dx.doi.org/10.1016/S0008-8846(03)00188-1.

7. Jones, TR. (2003) Metakaolin as pozzolanic addition to concrete. In: Barnes P, Bensted J, editors. Structure and performance of cements. England: Spon Press.

8. Hubertova, M.; Hela, R. (2007) The effect of metakaolin and silica fume on the properties of lightweight self-consolidating concrete. ACI Publication SP-243-3. Detroit: American Concrete Institute, 35-48.

9. Hassan, A.A.A; Lachemi, M; Hossain, K.M.A. (2012) Effect of metakaolin and silica fume on the durability of self-consolidating concrete. Cem. Con. Comp., 34, 801-807. http://dx.doi.org/10.1016/j.cemconcomp.2012.02.013.

10. Bai J.; Wild S.; Sabir B.B. (2003) Chloride ingress and strength loss in concrete with different PC-PFA-MK binder compositions exposed to synthetic seawater. Cem. Conc. Res., 33, 353-362. http://dx.doi.org/10.1016/S00088846(02)00961-4

11. Martin-Pérez, B.; Zibara, H.; Hooton, R.D.; Thomas, M.D.A. (2000) A study of the effect of chloride binding on service life predictions. Cem. Conc. Res., 30, 1215-1223. http://dx.doi.org/10.1016/S0008-8846(00)00339-2.

12. Linhua Jiang; Guohong huang; Jinxia X; Yeran Zhu; Lili Moa. (2012) Influence of chloride salt type on threshold level of reinforcement corrosion in simulated concrete pore solutions. Con. Build. Mat., 30, 516-521. http://dx.doi. org/10.1016/j.conbuildmat.2011.12.044.

13. Zhiguang Shi; Zhonghe Shui; Qiu Li; Haining Geng. (2015) Combined effect of metakaolin and sea water on performance and microstructures of concrete. Con. Build. Mat., 74, 57-64. http://dx.doi.org/10.1016/j.conbuildmat.2014. 10.023 .

14. Degirmenci, N.; Yilmaz, A. (2009) Use of diatomite as partial replacement for Portland cement in cement mortars. Con. Build. Mat., 23, 284-288. http://dx.doi.org/10.1016/j. conbuildmat.2007.12.008.

15. Rahhal, V.; Talero, R. (2009) Calorimetry of Portland cement with silica fume, diatomite and quartz additions. Con. Build. Mat., 23, 3367-3374. http://dx.doi.org/10.1016/j. conbuildmat.2009.06.003.

16. Aydin, A.C.; Gul, R. (2007) Influence of volcanic originated natural materials as additive on the setting time and some mechanical properties of concrete. Con. Build. Mat., 21, 1277-1281. http://dx.doi.org/10.1016/j.conbuildmat.2006. 02.011 .

17. Yilmaz, B.; Ediz, N. (2008) The use of raw and calcined diatomite in cement production. Cem. Con. Comp., 30, 202-211. http://dx.doi.org/10.1016/j.cemconcomp.2007. 08.003 .

18. Stamatakis, M.G; Csirik, G.; Bedelean, I.; Pedersen, S. (2003) The influence of biogenic-silica-rich rocks on the properties 
of blended cements. Cem. Con. Comp., 25, 177-184. http:// dx.doi.org/10.1016/S0958-9465(02)00019-7.

19. Young, J.F.; Mindess, S.; Gray, R.J.; Bentur, A. (1998) The Science and Technology of Civil Engineering Materials, Ed. Prentice Hall Inc., New Jersey.

20. Hewlett, P.C. (2001) Lea's Chemistry of Cement and Concrete, Ed. Butterworth-Heinemann, Oxford.

21. Rixom, R.; Mailvaganam, N. (1999) Chemical Admixtures for Concrete, Ed. E \& FN Spon, London.
22. Wild, S.; Khatib, J.M.; Jones, A. (1996) Relative strength, pozzolanic activity and cement hydration in superplasticized metakaolin concrete. Cem. Con. Res., 26, 1537-1544. http://dx.doi.org/10.1016/0008-8846(96)00148-2.

23. Michael, D.A.; Thomas, Phil.; Bamford, B., (1999) Modelling chloride diffusion in concrete: Effect of fly ash and slag. Cem. Con. Res., 29, 487-495. http://dx.doi.org/10.1016/S00088846(98)00192-6. 